\title{
Characteristics of short general internal medicine hospital stays: a multicentre cross-sectional study
}

\author{
Amol A. Verma MD MPhil, Yishan Guo MSc, Janice L. Kwan MD MPH, Lauren Lapointe-Shaw MD, \\ Shail Rawal MD MPH, Terence Tang MD, Adina Weinerman MD MHSc, Fahad Razak MD MSc
}

\section{Abstract}

Background: Short hospital stays may represent opportunities to avert unnecessary admissions or expedite inpatient care. To inform the design of interventions that target patients with potentially avoidable hospital admissions or brief stays, we examined the patient, physician and situational characteristics associated with short stays among patients admitted to general internal medicine wards and describe the use of hospital resources by these patients.

Methods: This was a multicentre cross-sectional study conducted between Apr. 1, 2012, and Mar. 31, 2015, at 5 teaching hospitals in Toronto. We included all general internal medicine admissions through the emergency department. We examined patient, physician and situational predictors of a short hospital stay, which was defined as the patient's being discharged home alive in 2 possible time windows: less than 24 hours, or 72 hours or less.

Results: The final study sample included 56055 admissions and 37700 unique patients. Patients discharged in less than 24 hours and in 72 hours or less accounted for 4245 (7.6\%) and 13442 (31.6\%) admissions, respectively. After we controlled for patient factors, patients of female physicians were less likely than those of male physicians to have stays lasting less than 24 hours (adjusted odds ratio [OR] $0.80,95 \%$ confidence interval [Cl] 0.74-0.86) or 72 hours or less (adjusted OR $0.82,95 \% \mathrm{Cl} 0.79-0.86$ ). Patients admitted at night or on a weekday were significantly more likely than those admitted at other times to have stays lasting less than 24 hours (night: adjusted OR 2.73, 95\% Cl 2.44-3.06; weekday: adjusted OR 1.26, 95\% Cl 1.17-1.36) or 72 hours or less (night: adjusted OR 1.29, 95\% Cl 1.22-1.37, weekday: adjusted OR 1.05, 95\% Cl 1.01-1.10). Among stays lasting less than 24 hours and 24-72 hours, intravenously administered medications were ordered for $2788(65.7 \%)$ and 10722 (79.8\%) patients, respectively, and computed tomography scans were performed for 1561 (36.8\%) and 5354 (39.1\%) patients, respectively.

Interpretation: Short general internal medicine hospital stays were common and were associated with patient, physician and situational factors. Interventions to avert hospital admission or reduce length of stay may be more effective if they are accessible outside typical working hours and provide access to intravenous therapy and radiological investigations.

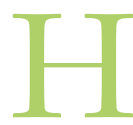

ospital care accounts for nearly $30 \%$ of health care costs in Canada. ${ }^{1}$ Given the high costs of hospital care, there is substantial interest in averting unnecessary hospital admissions and reducing length of stay. Interventions designed to avoid admission ${ }^{2}$ or reduce the length of stay have included hospital-at-home, ${ }^{3}$ short-stay or observation units, ${ }^{4-8}$ and rapid-access clinics. ${ }^{9}$ Patients with short stays may be candidates for these models of expedited and streamlined care.

Patient age, illness severity, level of comorbidity and functional status have all been associated with longer hospital stays. ${ }^{10-16}$ However, less is known about the situational and physician factors and resource use associated with short medical stays. The proportion of medical admissions associated with a short stay and the conditions that account for these short stays are also not well described. This information may highlight opportunities to improve care. To inform the design of interventions that target patients with potentially avoidable hospital admissions or brief stays, we examined the patient, physician and situational characteristics associated with short stays among patients admitted to general internal medicine wards. In addition, we describe the use of hospital resources by these patients.

\section{Methods}

\section{Design, setting and participants}

This was a multicentre cross-sectional study involving 5 academic hospitals in Toronto that were participating in the General Medicine Inpatient Initiative (GEMINI) ${ }^{17}$ The participating sites included St. Michael's Hospital, University Health

\section{Competing interests: None declared.}

This article has been peer reviewed.

Correspondence to: Amol Verma, amol.verma@mail.utoronto.ca CMAJ Open 2019. DOI:10.9778/cmajo.20180181 
Network (Toronto Western Hospital and Toronto General Hospital), Mount Sinai Hospital and Sunnybrook Health Sciences Centre. All Ontario residents have access to publicly funded essential hospital services. The participating hospitals cater to a diverse urban population and range in size from 433 to 1325 acute inpatient beds. In 2010-2015, general internal medicine patients accounted for $39 \%$ of emergency department admissions to hospital and $24 \%$ of hospital bed-days. ${ }^{17}$

We included all patients admitted to the general internal medicine service through the emergency department and discharged between Apr. 1, 2012, and Mar. 31, 2015. The general internal medicine services operate on a hospitalist model, are staffed predominantly by internists, and include clinical teaching units, nonteaching hospitalist services and 1 family medicine inpatient unit. ${ }^{17}$ Attending physicians typically rotate in 1to 4-week blocks of clinical service. We excluded patients who were missing a provincial health insurance number $(n=646$ [1.1\%]), because this were needed to ascertain previous use of health care services. We also excluded patients who were missing data on the sex of the most responsible physician $(n=1524$ [2.6\%]) or ambulance transport to hospital $(n=3[<0.01 \%])$.

\section{Data sources}

Data for GEMINI were collected from administrative sources and hospital information systems and were linked at the individual patient level, as has previously been described. ${ }^{17}$ Patient demographic characteristics and clinical characteristics for each admission were collected from hospital administrative databases as reported for the Discharge Abstract Database and National Ambulatory Care Reporting System of the Canadian Institute for Health Information. ${ }^{18}$ These data include patient diagnoses and interventions relating to the inpatient and emergency portion of patients' hospital visits, coded according to the enhanced Canadian version of the International Statistical Classification of Diseases and Related Health Problems, 10th revision (ICD-10-CA) and the Canadian Classification of Health Interventions. Laboratory and radiology results and information on blood transfusions and in-hospital medications were extracted from hospital information systems. Laboratory data were cleaned by removing nonnumeric values.

Each hospital admission was attributed to a single "most responsible physician" as per the Discharge Abstract Database, defined as the attending physician who is "responsible for the care and treatment of the patient for the majority of the visit to the health care facility." 18 Physician characteristics were collected from the College of Physicians and Surgeons of Ontario physician information database, which is publicly available. ${ }^{19}$

\section{Outcomes and measures}

The main outcome was discharge home alive after a short hospital stay. There is no universally accepted definition of what constitutes a short hospital stay, but commonly accepted definitions include stays of 24 or 72 hours, and short-stay units are often designed for these durations. ${ }^{4,10,13}$ Therefore, we conducted 2 parallel analyses to compare longer hospital stays to those lasting 1) less than 24 hours and 2) 72 hours or less. We defined hospital length of stay as the time from hos- pital admission to discharge. Patients who died in hospital, left hospital against medical advice, or were transferred to another acute inpatient, rehabilitation or palliative care facility were categorized as having a longer stay.

We examined patient, physician and situational factors associated with a short hospital stay. Patient characteristics included age, sex, Charlson Comorbidity Index score, ${ }^{20}$ Laboratory-based Acute Physiology Score (LAPS) (a measure of illness severity that has been validated as a predictor of death), ${ }^{21,22}$ ambulance transport, admission to general internal medicine at a study site in the 30 previous days and fiscal year of admission. We selected these patient characteristics because patient age, illness severity and level of comorbidity have all been associated with a longer hospital stay. ${ }^{10-16}$ Fiscal year was included to account for secular trends in hospital length of stay. Physician characteristics included years since medical school graduation and sex because physician experience and sex have been associated with differences in physician practice and quality of inpatient care. ${ }^{23-25}$ Situational factors included the day of admission (weekend or weekday), time of admission (day [0800-1659:59], evening [1700-2400] or night [0000:010759:59]), admission to a short-stay unit (which was available at 2 participating hospitals) and the volume of admissions to general internal medicine in the previous 12 hours (prespecified as a measure of the workload of the admitting general internal medicine physicians in the emergency department). We examined these situational factors because the quality of hospital care has been shown to differ on the weekend and after hours ${ }^{26-29}$ and with changes in physician workload. ${ }^{30}$

We categorized each admission into a clinical condition based on the patient's principal discharge diagnosis using the Clinical Classifications Software tool, ${ }^{31}$ which aggregates ICD-10 diagnoses into 285 mutually exclusive clinically relevant categories. We report the number of admissions in which at least 1 of the following was used: order for intravenously administered medication, radiography, computed tomography (CT), ultrasonography, magnetic resonance imaging, red blood cell transfusion, endoscopy procedure or bronchoscopy procedure. We also report the mean time spent in the emergency department and the proportion of patients admitted to the intensive care unit.

\section{Statistical analysis}

We first compared patient characteristics among those discharged home alive in less than 24 hours, 24-72 hours and more than 72 hours using $\chi^{2}$ and Kruskall-Wallis tests for categorical and continuous variables, respectively. Second, we performed logistic regression with generalized estimating equations to account for clustering effects of admitted patients cared for by the same physicians. Our primary analysis considered each hospital admission to be distinct and did not account for clustering related to repeat visits by individual patients. We chose this approach because the primary focus of our study was to describe the use of health care services among short hospital stays. We performed a sensitivity analysis to explore the clustering effects related to patients with multiple admissions during the study period. We applied the same logistic regression with generalized 
estimating equations on a restricted sample where only 1 admission was included for each unique patient. For patients with multiple admissions, we used statistical software to randomly select 1 admission to avoid the biasing effects of choosing the first or last admission. We performed 2 sets of analysis to examine the 2 short-stay time windows. Short stays were defined as stays of less than 24 hours and were compared with all other stays, and then short stays were defined as stays of 72 hours or less. To explore whether patient characteristics contributed to differences in short stays that were related to situational factors, we compared patient characteristics among short stays at different times of the day or on the weekend using $\chi^{2}$ and KruskallWallis tests. Third, we compared the prevalence of discharge diagnoses (categorized according to Clinical Classifications Software condition) among patients discharged home alive in less than 24 hours and those with stays lasting more than 72 hours. To identify the discharge diagnoses that were more common among short and long stays, we ranked diagnoses by the difference in prevalence between short and long stays. Finally, we report the hospital resources used by patients with stays of different durations. All analyses were performed with $\mathrm{R}$ version 3.3.2 (R Foundation for Statistical Computing).

\section{Ethics approval}

Ethics approval was obtained from the research ethics board of all participating hospitals.

\section{Results}

The final study sample included 56055 admissions and 37700 unique patients. Overall, 10360 admissions (18.5\%) resulted in transfer to another inpatient, rehabilitation or palliative care facility, 3264 admissions (5.8\%) ended with death in hospital, and 1253 admissions (2.2\%) ended with the patient's leaving against medical advice. Patients were discharged home alive within 24 hours in 4245 admissions (7.6\%) and within 24-72 hours in 13442 admissions (24.0\%). The overall median length of stay was 4.4 days (interquartile range $2.25-8.54 \mathrm{~d}$ ).

\section{Patient characteristics associated with short stay}

Compared to patients with longer stays, patients with shorter stays were significantly younger, had lower comorbidity, were less likely to arrive by ambulance, had a lower average LAPS and were less likely to have a recent prior admission (Table 1). In multivariable regression models, increasing age, higher

\begin{tabular}{|c|c|c|c|c|}
\hline \multirow[b]{2}{*}{ Characteristic } & \multicolumn{3}{|c|}{ Duration of stay; no. $(\%)$ of patients* } & \multirow[b]{2}{*}{$p$ value $\ddagger$} \\
\hline & $\begin{array}{c}<24 h \\
n=4245\end{array}$ & $\begin{array}{c}24-72 \mathrm{~h} \\
n=13442\end{array}$ & $\begin{array}{c}>72 \mathrm{~h} \dagger \\
n=38368\end{array}$ & \\
\hline Age, yr, median (IQR) & $63(45-78)$ & $67(50-81)$ & $74(59-84)$ & $<0.001$ \\
\hline Female sex & $2155(50.8)$ & $6722(50.0)$ & $19026(49.6)$ & 0.3 \\
\hline \multicolumn{2}{|l|}{$\begin{array}{l}\text { Charlson Comorbidity Index } \\
\text { score }\end{array}$} & & & $<0.001$ \\
\hline 0 & $1846(43.5)$ & $4666(34.7)$ & $8809(23.0)$ & \\
\hline 1 & $962(22.7)$ & $3061(22.8)$ & $7737(20.2)$ & \\
\hline 2 & $557(13.1)$ & $2210(16.4)$ & $6785(17.7)$ & \\
\hline$\geq 3$ & $880(20.7)$ & $3505(26.1)$ & 15037 (39.2) & \\
\hline Transported via ambulance & $1531(36.1)$ & $5700(42.4)$ & $21533(56.1)$ & $<0.001$ \\
\hline $\begin{array}{l}\text { Admitted to general internal } \\
\text { medicine at a study site in } \\
\text { prior } 30 \mathrm{~d}^{*}\end{array}$ & $372(8.8)$ & $1283(9.5)$ & $5315(13.8)$ & $<0.001$ \\
\hline $\begin{array}{l}\text { Laboratory-based Acute } \\
\text { Physiology Score, mean } \\
\pm \text { SD }\end{array}$ & $13.0 \pm 12.4$ & $16.3 \pm 13.9$ & $21.4 \pm 17.1$ & $<0.001$ \\
\hline Admitted on weekend & $929(21.9)$ & $3516(26.2)$ & $10152(26.4)$ & $<0.001$ \\
\hline Time of admission & & & & $<0.001$ \\
\hline Day (0800-1659:59) & $398(9.4)$ & $2832(21.1)$ & $8398(21.9)$ & \\
\hline Evening (1700-2400) & $1795(42.3)$ & $5156(38.4)$ & $14828(38.6)$ & \\
\hline Night (0000:01-0759:59) & $2052(48.3)$ & $5454(40.6)$ & $15142(39.5)$ & \\
\hline \multicolumn{5}{|c|}{$\begin{array}{l}\text { Note: IQR = interquartile range, } \mathrm{SD}=\text { standard deviation. } \\
\text { *Except where noted otherwise. } \\
\text { †Patients who left hospital against medical advice, died or were transferred to another acute inpatient, rehabilitation or palliative care } \\
\text { facility were categorized as having a stay of more than } 72 \text { hours. } \\
\neq \chi^{2} \text { analysis for categorical variables, Kruskall-Wallis test for continuous variables. }\end{array}$} \\
\hline
\end{tabular}


Charlson Comorbidity Index score, transport via ambulance, recent admission and a higher LAPS were all associated with a significantly lower likelihood of a short stay (either $<24$ h or $\leq 72 \mathrm{~h}$ ) (Table 2).

\section{Physician characteristics associated with short stay}

The number of years since physician graduation was not significantly associated with the likelihood of a short stay under either definition (Table 2). Patients of female physicians were significantly less likely than those of male physicians to have stays lasting either less than 24 hours (adjusted odds ratio [OR] $0.80,95 \%$ CI $0.74-0.86$ ) or 72 hours or less (adjusted OR $0.82,95 \%$ CI 0.79-0.86).

\section{Situational factors associated with short stay}

A short stay (either $<24 \mathrm{~h}$ or $\leq 72 \mathrm{~h}$ ) was more likely for patients admitted in the evening or night than for those admitted during the day (Table 2). A short stay was signifi- cantly more likely for patients admitted on a weekday than for those admitted on the weekend, although this effect was stronger for stays of less than 24 hours (adjusted OR 1.26, 95\% CI 1.17-1.36) than for those lasting 72 hours or less (adjusted OR 1.05, 95\% CI 1.01-1.10). There was no significant association between short stays and the number of patients admitted to general internal medicine in the previous 12 hours (Table 2).

Among patients with a short stay $(<24 \mathrm{~h}$ or $\leq 72 \mathrm{~h})$, those who were admitted in the evening or at night were older than those admitted in the daytime $(p<0.001)$, but the 2 groups were not consistently different in comorbidity level or illness severity (supplementary Tables S1 and S2, Appendix 1, available at www.cmajopen.ca/content/7/1/E47/suppl/DC1). Among patients with a stay lasting 72 hours or less, those admitted on the weekend had more severe illness than those admitted on a weekday, indicated by greater rates of ambulance transport (1928 [43.4\%] v. 5303 [40.0\%], $p<0.001)$ and

Table 2: Univariate and multivariable regression models of patient, physician and situational characteristics associated with a short stay after admission to general internal medicine

\begin{tabular}{|c|c|c|c|c|}
\hline \multirow[b]{2}{*}{ Characteristic } & \multicolumn{2}{|c|}{ Model A: $<24 \mathrm{~h}$} & \multicolumn{2}{|c|}{ Model $\mathrm{B}: \leq 72 \mathrm{~h}$} \\
\hline & $\begin{array}{l}\text { Univariate } \mathrm{OR}^{\star} \\
\qquad(95 \% \mathrm{Cl})\end{array}$ & $\begin{array}{l}\text { Multivariable adjusted } \\
\qquad \mathrm{OR}^{\star}(95 \% \mathrm{Cl})\end{array}$ & $\begin{array}{l}\text { Univariate OR* } \\
\qquad(95 \% \mathrm{Cl})\end{array}$ & $\begin{array}{c}\text { Multivariable adjusted } \\
\mathrm{OR}^{*}(95 \% \mathrm{Cl})\end{array}$ \\
\hline \multicolumn{5}{|l|}{ Patients } \\
\hline Age & $0.98(0.98-0.98)$ & $0.99(0.99-0.99)$ & $0.98(0.98-0.98)$ & $0.99(0.99-0.99)$ \\
\hline Female sex & $1.06(0.98-1.14)$ & $0.96(0.90-1.02)$ & $1.05(1.01-1.10)$ & $0.97(0.94-1.01)$ \\
\hline \multicolumn{5}{|l|}{ Charlson Comorbidity Index score } \\
\hline 0 & $3.10(2.79-3.44)$ & $1.97(1.79-2.16)$ & $2.77(2.62-2.94)$ & $1.75(1.66-1.84)$ \\
\hline 1 & $1.98(1.76-2.22)$ & $1.63(1.47-1.79)$ & $1.91(1.79-2.03)$ & $1.54(1.46-1.62)$ \\
\hline 2 & $1.33(1.16-1.52)$ & $1.20(1.08-1.34)$ & $1.46(1.36-1.56)$ & $1.29(1.21-1.36)$ \\
\hline Not transported via ambulance & $2.03(1.88-2.20)$ & $1.44(1.34-1.54)$ & $1.92(1.84-2.00)$ & $1.47(1.41-1.53)$ \\
\hline $\begin{array}{l}\text { Admitted to general internal medicine } \\
\text { at a study site in prior } 30 \mathrm{~d}^{*}\end{array}$ & $0.54(0.44-0.65)$ & $0.84(0.75-0.94)$ & $0.53(0.48-0.59)$ & $0.77(0.73-0.82)$ \\
\hline $\begin{array}{l}\text { Laboratory-based Acute Physiology } \\
\text { Score }\end{array}$ & $0.96(0.96-0.97)$ & $0.97(0.97-0.98)$ & $0.97(0.97-0.97)$ & $0.98(0.98-0.98)$ \\
\hline \multicolumn{5}{|l|}{ Physicians } \\
\hline Female sex & $0.83(0.77-0.91)$ & $0.80(0.74-0.86)$ & $0.84(0.80-0.88)$ & $0.82(0.79-0.86)$ \\
\hline Years since graduation & $1.00(1.00-1.01)$ & $1.00(1.00-1.00)$ & $1.00(1.00-1.00)$ & $1.00(1.00-1.00)$ \\
\hline \multicolumn{5}{|l|}{ Situational } \\
\hline Admitted weekday & $1.34(1.23-1.47)$ & $1.26(1.17-1.36)$ & $1.09(1.03-1.14)$ & $1.05(1.01-1.10)$ \\
\hline Admitted evening & $2.53(2.22-2.88)$ & $2.61(2.33-2.92)$ & $1.20(1.13-1.28)$ & $1.24(1.17-1.30)$ \\
\hline Admitted night & $2.93(2.57-3.33)$ & $2.73(2.44-3.06)$ & $1.31(1.23-1.39)$ & $1.29(1.22-1.37)$ \\
\hline $\begin{array}{l}\text { Admissions to general internal } \\
\text { medicine in prior } 12 \mathrm{~h}\end{array}$ & $1.05(1.04-1.06)$ & $1.01(1.00-1.02)$ & $1.02(1.02-1.03)$ & $1.00(1.00-1.01)$ \\
\hline Admitted to short-stay unit & $2.26(2.03-2.52)$ & $1.56(1.39-1.75)$ & $3.06(2.83-3.31)$ & $2.35(2.17-2.54)$ \\
\hline Fiscal year of admission & $1.09(1.04-1.14)$ & $1.09(1.05-1.14)$ & $1.05(1.03-1.08)$ & $1.05(1.03-1.08)$ \\
\hline
\end{tabular}


greater LAPS (mean 16.04 v. $15.35, p=0.004$ ), but these differences were not seen among patients with stays lasting less than 24 hours (Supplementary Tables S3 and S4, Appendix 1).

When only 1 admission was included per patient, there were no meaningful changes in the effect size or statistical significance of the results of regression models (Supplementary Table S5, Appendix 1). This suggests that clustering effects at the patient level did not substantially influence the observed results.

\section{Common discharge diagnoses}

Discharge diagnoses differed between short and long stays (Table 3). Nonspecific chest pain, syncope, essential hypertension, intestinal infection, and dizziness and vertigo were more common among stays lasting less than 24 hours. No single diagnosis represented more than $3.9 \%$ of stays lasting less than 24 hours, $6.0 \%$ of stays lasting $24-72$ hours or $5.9 \%$ of stays lasting more than 72 hours.

\section{Resource use in short stays}

Patients with hospital stays lasting less than 24 hours and those with stays of 24-72 hours spent on average 14.8 (standard deviation 6.6) hours and 15.7 (standard deviation 9.0) hours, respectively, in the emergency department (Table 4). Intravenously administered medications were ordered for 2788 patients $(65.7 \%)$ with stays of less than 24 hours and 10722 patients (79.8\%) with stays of 24-72 hours, and CT scans were performed for 1561 (36.8\%) and 5354 (39.1\%), respectively. A total of 1925 patients (10.9\%) with stays lasting 72 hours or less did not receive any intravenous therapy, CT scans, magnetic resonance imaging, ultrasonography, endoscopy, bronchoscopy or intensive care.

\section{Interpretation}

This large multicentre study showed that short stays after admission to general internal medicine were common and were associated with both patient and nonpatient factors. We found that $31.6 \%$ of general internal medicine stays lasted 72 hours or less, and $7.6 \%$ lasted less than 24 hours. After we controlled for other factors, short stays were more common among patients admitted during the night or on weekdays and among those cared for by male physicians. Our finding that physician and situational factors were associated with short stays highlights opportunities to further streamline care.

Several interventions such as short-stay or observation units, ${ }^{4-8}$ hospital-at-home ${ }^{3}$ and rapid-access clinics ${ }^{9}$ have been directed toward patients with short hospital stays. ${ }^{2}$ Our findings offer insights for the design and delivery of these interventions for medical patients. First, we identified conditions that were more common among general internal medicine patients with short and long stays. It may be difficult to organize programs around individual diseases, because no single condition accounted for more than $6.0 \%$ of short stays, consistent with the heterogeneity of this population. ${ }^{32}$ However, certain conditions were more common among patients with short stays: chest pain, syncope, hypertension, intestinal infection and vertigo. Several of these represent conditions in which patients have a brief stay for clinical monitoring. The proliferation of digital and mobile technologies may allow

\begin{tabular}{|c|c|c|c|}
\hline \multicolumn{4}{|c|}{$\begin{array}{l}\text { Table 3: Discharge diagnoses that were more common among short and long } \\
\text { hospital stays }\end{array}$} \\
\hline \multirow[b]{2}{*}{ Diagnosis } & \multicolumn{2}{|c|}{$\begin{array}{l}\text { Duration of stay; no. (\%) of } \\
\text { admissions }\end{array}$} & \multirow{2}{*}{$\begin{array}{l}\text { Absolute } \\
\text { difference }\end{array}$} \\
\hline & $<24 \mathrm{~h}$ & $>72 \mathrm{~h}$ & \\
\hline \multicolumn{4}{|c|}{ More common among short stays } \\
\hline Nonspecific chest pain & $167(3.9)$ & $194(0.5)$ & 3.4 \\
\hline Syncope & $124(2.9)$ & $399(1.0)$ & 1.9 \\
\hline Essential hypertension & $90(2.1)$ & $158(0.4)$ & 1.7 \\
\hline Intestinal infection & $163(3.8)$ & $822(2.1)$ & 1.7 \\
\hline Dizziness or vertigo & $92(2.2)$ & $201(0.5)$ & 1.6 \\
\hline \multicolumn{4}{|c|}{ More common among long stays } \\
\hline Congestive heart failure & $101(2.4)$ & $2251(5.9)$ & 3.5 \\
\hline Sepsis & $7(0.2)$ & $1016(2.6)$ & 2.5 \\
\hline $\begin{array}{l}\text { Delirium, dementia, cognitive } \\
\text { disorder }\end{array}$ & $62(0.2)$ & $1444(3.8)$ & 2.3 \\
\hline Stroke & $27(0.6)$ & $996(2.6)$ & 2.0 \\
\hline Urinary tract infection & $123(2.9)$ & $1823(4.8)$ & 1.9 \\
\hline \multicolumn{4}{|c|}{$\begin{array}{l}{ }^{*} \text { Calculated among patients discharged alive in less than } 24 \text { hours and among those who died in hospital or } \\
\text { whose hospital stay exceeded } 72 \text { hours. Diagnoses were ranked by the difference in prevalence between } \\
\text { short and long stays, and the diagnoses with largest absolute differences between short and long stays are } \\
\text { reported. }\end{array}$} \\
\hline
\end{tabular}




\begin{tabular}{|c|c|c|c|}
\hline \multirow[b]{2}{*}{ Resource } & \multicolumn{3}{|c|}{ Duration of stay; no. (\%) of admissions ${ }^{*}$} \\
\hline & $<24 \mathrm{~h}$ & $24-72 \mathrm{~h}$ & $>72 \mathrm{~h}$ \\
\hline $\begin{array}{l}\text { Length of time in emergency } \\
\text { department, } h \text {, mean } \pm S D\end{array}$ & $14.8 \pm 6.6$ & $15.7 \pm 9.0$ & $16.4 \pm 9.9$ \\
\hline $\begin{array}{l}\text { Intravenously administered } \\
\text { medication } \dagger\end{array}$ & $2788(65.7)$ & $10722(79.8)$ & $33022(86.1)$ \\
\hline Radiography† & $2803(66.0)$ & $10013(74.5)$ & $33260(86.7)$ \\
\hline Computed tomography $\dagger$ & $1561(36.8)$ & $5254(39.1)$ & $21772(56.7)$ \\
\hline Ultrasonography† & $418(9.8)$ & $2363(17.6)$ & $12110(31.6)$ \\
\hline Magnetic resonance imaging† & $144(3.4)$ & $842(6.3)$ & $4983(13.0)$ \\
\hline Red blood cell transfusion $†$ & $86(2.0)$ & $593(4.4)$ & $4522(11.8)$ \\
\hline Endoscopy† & $92(2.2)$ & $1053(7.8)$ & $4037(10.5)$ \\
\hline Bronchoscopy & $1(0.0)$ & $39(0.3)$ & $965(2.5)$ \\
\hline Intensive care unit admission & $18(0.4)$ & $101(0.8)$ & $2509(6.5)$ \\
\hline No advanced interventions $\ddagger$ & $779(18.4)$ & $1146(8.5)$ & $1347(3.5)$ \\
\hline \multicolumn{4}{|c|}{$\begin{array}{l}\text { Note: } S D=\text { standard deviation. } \\
\text { *Except where noted otherwise. } \\
\text { †Number of admissions in which at least } 1 \text { of this test or treatment was used. } \\
\text { †Number of admissions in which none of the following tests or treatments were used: intravenous } \\
\text { medication, computed tomography, ultrasonography, magnetic resonance imaging, endoscopy, } \\
\text { bronchoscopy or intensive care unit admission. }\end{array}$} \\
\hline
\end{tabular}

some of these patients to be monitored in settings outside of acute care hospitals. Second, intravenous therapy and radiologic and endoscopic investigations were important in the care of patients with short stays. Providing expedited access to these treatments and investigations may be an important component of short-stay interventions. Third, patients were more likely to have a short stay when they were admitted in the evening or at night. Thus, accessing short-stay interventions should ideally be possible outside of typical working hours.

Short stays may represent avoidable admissions or efficient stays that would otherwise have been longer. This may explain why short stays were more common in the evening and at night but less common on the weekend in the current study. Admissions at participating hospitals are performed by in-house internal medicine residents, who typically review cases with staff physicians before discharging patients. Residents may prefer not to "disturb" their staff physician after hours and elect to review the case the next morning rather than discharge a patient during the night. It may also be difficult to coordinate aspects of a patient's discharge overnight, resulting in a brief but potentially avoidable hospital stay. On the weekend, it may be difficult to coordinate patient discharges, or patients may experience delays in receiving tests and/or procedures. ${ }^{26,27}$ Furthermore, covering physicians on the weekend may be less likely to discharge a patient with whom they are less familiar. Short stays may be less likely on weekends because patients who would otherwise be discharged remain in hospital, and short stays may be more likely on weeknights as patients who would otherwise be discharged home are admitted overnight in the emergency department.
In the present study, short stays among patients admitted in the evening, at night or on weekends did not occur for patients with lower comorbidity or less severe illness, as might be expected if admissions were primarily due to logistical factors. Nevertheless, our findings are consistent with a body of literature suggesting differential access to care and patient outcomes at night and on weekends compared to weekdays, ${ }^{26-29}$ and we identified an interesting difference between nights and weekends.

Patients of female physicians were less likely to have short stays even after we controlled for years of physician practice and numerous patient factors such as age, comorbidities and illness severity. The validity of the comparison between male and female physicians is strengthened in this cohort because all patients were admitted nonelectively through the emergency department, and, thus, physician assignment occurred through a pseudorandom process, mitigating selection effects, as in the observational study by Tsugawa and colleagues. ${ }^{23}$ Although patient outcomes may differ between hospitalists and nonhospitalists, ${ }^{33}$ all physicians in our sample were hospitalists and almost all physicians were internists. Thus, sexrelated differences were not likely to be due to differences in specialty or patient case-mix. Recent analyses suggest that patients of female physicians may have better outcomes than those of male physicians. ${ }^{23}$ In the absence of analyses regarding mortality and readmission rates, we cannot comment on the possible relation between shorter length of stay and quality of care. Future research should seek to understand whether female physicians are more likely to discharge patients directly from the emergency department without hospital admission 
or less likely to discharge patients quickly from hospital, and whether such decisions contribute to differences in patient outcomes.

\section{Limitations}

There are several important limitations to our study. First, we included only general internal medicine patients, not all medical admissions. We chose to focus on general internal medicine because it is a large inpatient service in our hospitals and our objective was to understand models of care. Second, we included 5 teaching hospitals, and, thus, our results may not be generalizable to nonteaching sites where models of care and staffing differ. Although our study was conducted in Canada, the fact that the median length of stay (4.4 d) was similar to that in studies in Europe and the United States 34,35 supports the generalizability of our findings. Third, we examined the characteristics only of attending physicians, not medical residents. We felt this was appropriate because most discharge decisions are approved by attending physicians, who are ultimately responsible for the decisions made by their trainees. Moreover, because residents rotate across many attending physicians and thus over large samples, the effects of residents would be balanced across attending physicians. Fourth, we were unable to collect data about inpatient subspecialty consultation, patient living situation, caregiver support, functional status or socioeconomic status, which likely have important effects on hospital length of stay. Fifth, care in general internal medicine is often delivered in teams, and multiple physicians may care for individual patients. The "most responsible physician" may not always be the discharging physician, and misattribution may have occurred in our models. However, error resulting from this misclassification would be nondifferential between physicians and unlikely to affect our results. Moreover, handovers are less likely for patients with shorter stays. Finally, we did not collect data for patients who were seen by the general internal medicine service in the emergency department but not admitted to hospital. However, most patients referred to general internal medicine are ultimately admitted to hospital, and relatively few patients are discharged directly from the emergency department.

\section{Conclusion}

Short hospital stays after admission to general internal medicine were common. They occurred more frequently when patients were admitted in the evening or at night and when the physicians was male. Interventions to streamline care for these patients and avert hospital admission may be more effective if they are accessible outside of typical working hours and provide access to intravenous therapy and radiological and endoscopic interventions.

\section{References}

1. National health expenditure trends, 1975 to 2018. Ottawa: Canadian Institute for Health Information; 2018. Available: https://www.cihi.ca/sites/default/files/ document/nhex-trends-narrative-report-2018-en-web.pdf (accessed 2019 Jan. 15).

2. Conley J, O'Brien CW, Leff BA, et al. Alternative strategies to inpatient hospitalization for acute medical conditions: a systematic review. FAMA Intern Med 2016;176:1693-702.
3. Jeppesen E, Brurberg KG, Vist GE, et al. Hospital at home for acute exacerbations of chronic obstructive pulmonary disease. Cochrane Database Syst Rev 2012;(5):CD003573

4. Galipeau J, Pussegoda K, Stevens A, et al. Effectiveness and safety of short-stay units in the emergency department: a systematic review. Acad Emerg Med 2015; 22:893-907.

5. Ross MA, Naylor S, Compton S, et al. Maximizing use of the emergency department observation unit: a novel hybrid design. Ann Emerg Med 2001;37: 267-74.

6. Mace SE, Graff L, Mikhail M, et al. A national survey of observation units in the United States. Am 7 Emerg Med 2003;21:529-33.

7. Blecker S, Gavin NP, Park H, et al. Observation units as substitutes for hospitalization or home discharge. Ann Emerg Med 2016;67:706-713.e2.

8. Baugh CW, Venkatesh AK, Hilton JA, et al. Making greater use of dedicated hospital observation units for many short-stay patients could save $\$ 3.1$ billion a year. Health Aff (Millwood) 2012;31:2314-23.

9. O'Brien E, Priglinger ML, Bertmar C, et al. Rapid access point of care clinic for transient ischemic attacks and minor strokes. 7 Clin Neurosci 2016;23: $106-10$

10. Lucas BP, Kumapley R, Mba B, et al. A hospitalist-run short-stay unit: features that predict length-of-stay and eventual admission to traditional inpatient services. 7 Hosp Med 2009;4:276-84.

11. Caterino JM, Hoover EM, Moseley MG. Effect of advanced age and vital signs on admission from an ED observation unit. Am 7 Emerg Med 2013;31:1-7.

12. Basic D, Khoo A. Admission variables predicting short lengths of stay of acutely unwell older patients: relevance to emergency and medical short-stay units. Aust Health Rev 2009;33:502-12.

13. Yong TY, Li JYZ, Roberts S, et al. The selection of acute medical admissions for a short-stay unit. Intern Emerg Med 2011;6:321-7.

14. Powter L, Beale A, Probert B, et al. Development and validation of a tool to select patients for admission to medical short stay units. Clin Med (Lond) 2014; 14:371-5.

15. Dinh MM, Bein KJ, Byrne CM, et al. Deriving a prediction rule for short stay admission in trauma patients admitted at a major trauma centre in Australia. Emerg Med 7 2014;31:263-7.

16. Formiga F, Chivite D, Manito N, et al. Admission characteristics predicting longer length of stay among elderly patients hospitalized for decompensated heart failure. Eur f Intern Med 2008;19:198-202.

17. Verma AA, Guo Y, Kwan JL, et al. Patient characteristics, resource use and outcomes associated with general internal medicine hospital care: the General Medicine Inpatient Initiative (GEMINI) retrospective cohort study. CMA7 Open 2017;5:E842-9.

18. DAD abstracting manual, 2015-2016 edition. Ottawa: Canadian Institute for Health Information; 2015.

19. Public information and services: find a doctor. Toronto: College of Physicians and Surgeons of Ontario; 2017. Available: www.cpso.on.ca/Public-Information -Services/Find-a-Doctor (accessed 2017 Dec. 12).

20. Quan H, Li B, Couris CM, et al. Updating and validating the Charlson Comorbidity Index and score for risk adjustment in hospital discharge abstracts using data from 6 countries. Am 7 Epidemiol 2011;173:676-82.

21. Escobar GJ, Greene JD, Scheirer P, et al. Risk-adjusting hospital inpatient mortality using automated inpatient, outpatient, and laboratory databases. Med Care 2008;46:232-9.

22. van Walraven C, Escobar GJ, Greene JD, et al. The Kaiser Permanente inpatient risk adjustment methodology was valid in an external patient population. 7 Clin Epidemiol 2010;63:798-803.

23. Tsugawa Y, Jena AB, Figueroa JF, et al. Comparison of hospital mortality and readmission rates for Medicare patients treated by male vs female physicians. 7AMA Intern Med 2017;177:206-13.

24. McAlister FA, Youngson E, Bakal JA, et al. Physician experience and outcomes among patients admitted to general internal medicine teaching wards. CMAJ 2015;187:1041-8.

25. Choudhry NK, Fletcher RH, Soumerai SB. Systematic review: the relationship between clinical experience and quality of health care. Ann Intern Med 2005; 142:260-73

26. Bell CM, Redelmeier DA. Waiting for urgent procedures on the weekend among emergently hospitalized patients. Am 7 Med 2004;117:175-81.

27. Magid DJ, Wang Y, Herrin J, et al. Relationship between time of day, day of week, timeliness of reperfusion, and in-hospital mortality for patients with acute ST-segment elevation myocardial infarction. 7AMA 2005;294:803-12.

28. Concha OP, Gallego B, Hillman K, et al. Do variations in hospital mortality patterns after weekend admission reflect reduced quality of care or different patient cohorts? A population-based study. BM7 Qual Saf 2014;23:215-22.

29. Kostis WJ, Demissie K, Marcella SW, et al. Weekend versus weekday admission and mortality from myocardial infarction. N Engl f Med 2007;356: 1099-109.

30. Elliott DJ, Young RS, Brice J, et al. Effect of hospitalist workload on the quality and efficiency of care. 7AMA Intern Med 2014;174:786-93.

31. Healthcare Cost and Utilization Project. Beta Clinical Classifications Software (CCS) for ICD-10-CM/PCS. Rockville (MD): Agency for Healthcare Research and Quality; 2017. Available: https://www.hcup-us.ahrq.gov/ toolssoftware/ccs10/ccs10.jsp (accessed 2017 Oct. 27). 
32. Verma AA, Guo Y, Kwan JL, et al. Prevalence and costs of discharge diagnoses in inpatient general internal medicine: a multi-center cross-sectional study. 7 Gen Intern Med 2018;33:1899-904.

33. Rifkin WD, Holmboe E, Scherer H, et al. Comparison of hospitalists and nonhospitalists in inpatient length of stay adjusting for patient and physician characteristics. 7 Gen Intern Med 2004;19:1127-32.

34. Ong M, Bostrom A, Vidyarthi A, et al. House staff team workload and organization effects on patient outcomes in an academic general internal medicine inpatient service. Arch Intern Med 2007;167:47-52.

35. Kellett J, Deane B. The diagnoses and co-morbidity encountered in the hospital practice of acute internal medicine. Eur 7 Intern Med 2007;18:467-73.

Affiliations: Li Ka Shing Knowledge Institute (Verma, Guo, Razak), St. Michael's Hospital; Department of Medicine (Verma, Kwan, LapointeShaw, Rawal, Tang, Weinerman, Razak) and Institute of Health Policy, Management and Evaluation (Razak), University of Toronto; Department of Medicine (Kwan), Mount Sinai Hospital; Division of General Internal Medicine (Rawal), University Health Network, Toronto, Ont.; Trillium Health Partners (Tang), Mississauga, Ont.; Sunnybrook Health Sciences Centre (Weinerman), Toronto, Ont.; Harvard Center for Population and Development Studies (Razak), Cambridge, Mass.
Contributors: Amol Verma and Fahad Razak conceived and designed the study and led data collection and interpretation. Amol Verma drafted the manuscript. Yishan Guo contributed to the study design and analyzed the data. Janice Kwan, Lauren Lapointe-Shaw, Shail Rawal, Terence Tang and Adina Weinerman led data collection from their individual study sites. All of the authors contributed to data interpretation, critically revised the manuscript for important intellectual content, gave final approval of the version to be published and agreed to be accountable for all aspects of the work.

Funding: The General Medicine Inpatient Initiative (GEMINI) was supported by grants from the Green Shield Canada Foundation and the University of Toronto Division of General Internal Medicine. This study was supported by grant SMH-17-007 from the St. Michael's Hospital Medical Services Association Innovation Fund. Amol Verma is supported by funding from the Eliot Phillipson Clinician-Scientist Training Program, Department of Medicine, University of Toronto.

Supplemental information: For reviewer comments and the original submission of this manuscript, please see www.cmajopen.ca/content/7/1/ E47/suppl/DC1. 